\title{
Evaluación de la propiedad antimicrobial de las nanopartículas de oro sintetizadas con extractos de tamarindus indica $L$ y mangifera indica $L$
}

\section{Evaluation of the antimicrobial property of gold nanoparticles synthesized with tamarindus indica $L$ and mangifera indica $L$ extracts}

\author{
Naranjo-Herrera Ana María \\ Universidad Pontificia Bolivariana, Floridablanca, Colombia \\ Facultad de Ingeniería Ambiental \\ Correo: aniienaranjo.h@gmail.com \\ Correa-Torres Sandra Natalia \\ Universidad Pontificia Bolivariana, Floridablanca, Colombia \\ Facultad de Ingeniería Ambiental \\ Correo: sandra.correa@upb.edu.co
}

\author{
Herrera-Barros Adriana Patricia \\ Universidad de Cartagena, Cartagena, Colombia \\ Departamento de Investigación de la Facultad de Ingeniería \\ Correo: aherrerab2@unicartagena.edu.co
}

\section{Resumen}

Varios estudios han reportado el uso de nanopartículas de oro (AuNPs) en diferentes campos como inhibidor del crecimiento de microorganismos debido a que presentan propiedad antimicrobial. En el presente trabajo se evaluó la propiedad antimicrobial de las nanopartículas de oro biosintetizadas (AuNPs-Bio) a partir de extractos de plantas. Inicialmente se realizó la síntesis de nanopartículas de oro (AuNPs) por medio de un método biológico, en el cual se utilizaron los extractos de hojas de Tamarindus indica L. y Mangifera indica L., así como la sal precursora ácido cloroáurico (HAuCl4) con una concentración de 0.27mM. Posterior a la biosíntesis, se elaboraron las soluciones de AuNPs en medio acuoso con una concentración de $1.1 \mathrm{mg} / \mathrm{mL}$ y $0.9 \mathrm{mg} / \mathrm{mL}$, respectivamente. El análisis por SEM realizado a las AuNPs-Bio muestra un tamaño de partícula promedio de $52 \pm 5$ y $78 \pm 7 \mathrm{~nm}$, respectivo a cada extracto. La propiedad antimicrobial de las nanopartículas de oro se evaluó por medio de tres métodos: medio de cultivo modificado, sembrado en superficie y la prueba de difusión por disco, en los cuales se presentó crecimiento de bacterias y hongos debido a la baja concentración de las soluciones de AuNPs. Los resultados evidencian que sí se elaboran soluciones de nanopartículas más concentradas y con menos impurezas, estas son un candidato potencial para actuar como agentes antimicrobianos.

Descriptores: biosíntesis, nanopartículas, oro, propiedad antimicrobial.

\begin{abstract}
Several studies had been reported the use of gold nanoparticles in different fields as growing inhibitor of microorganisms due its antimicrobial property. In this work, was evaluated the antimicrobial property of biosynthesized gold nanoparticles (Bio-AuNPs) from plants extracts. First, gold nanoparticles synthesis was made by a biological method, in which were used leave extracts of Tamarindus indica L. and Mangifera indica L. and precursor salt of chloroauric acid ( $\mathrm{HAuCl} 4)$ with a concentration of $0.27 \mathrm{mM}$. After the biosynthesis of the nanoparticles, solutions were made with AuNPs in a aqueous medium with a concentration of $1.1 \mathrm{mg} / \mathrm{mL}$ and $0.9 \mathrm{mg} / \mathrm{mL}$ each. The SEM analysis on the Bio-AuNPs showed an average particle size of $52 \pm 5$ and $78 \pm 7 \mathrm{~nm}$ for each extract. The antimicrobial property of the gold nanoparticles was evaluated by three methods: medium of modified culture, surface culture and test by disk diffusion, in which there were bacteria and fungi growings due the low concentration of the solution of the AuNps. The results showed that solutions with higher concentration of AuNps will be potential candidates to act as antimicrobian agent.
\end{abstract}

Keywords: biosynthesis, nanoparticles, gold, antimicrobial property. 


\section{INTRODUCCIÓN}

Actualmente el diseño, elaboración e implementación de nanopartículas de oro ha presentado un aumento significativo a nivel global, empezando por la variedad de métodos empleados para su formación. Los procedimientos actuales que permiten la elaboración de estos nanomateriales se clasifican en cuatro categorías: mecánicos, físicos, químicos y biológicos (González et al., 2009; Aguilar, 2009).

El método de síntesis biológica (biosíntesis) es un método amigable con el medio ambiente, donde se involucran levaduras, extractos de plantas o microorganismos como las bacterias y hongos; los cuales logran la reducción de varios tipos de iones metálicos (Sastry et al., 2003). Los organismos vivos pueden llegar a producir nanopartículas intra o extracelular, donde esta última se implementa mayormente por los investigadores debido a su bajo costo y por ser adaptable (Basavaraja et al., 2008). El empleo de extractos de plantas, como en el presente proyecto, puede ser una vía más rápida que la implementación de microorganismos para la formación de nanopartículas de oro. En este caso, los compuestos orgánicos como terpenos, flavonoides, enzimas, proteínas y cofactores presentes en las plantas, actúan como agentes reductores de los nanomateriales.

La figura 1 ilustra el proceso de biosíntesis de nanopartículas metálicas a partir de extractos de plantas. Iniciando por su estado iónico, pasando a un estado metálico con ayuda de agentes reductores y posteriormente por el crecimiento de esas partículas en estado metálico (aglomeración), hasta llegar a un estado estable.

Con el fin de satisfacer las diferentes necesidades en los campos de la bioingeniería, biomédica, seguridad alimenticia y desarrollo sostenible, la implementación de las nanopartículas es una de las soluciones o alternativas (Arizaga et al., 2010). En la biomédica se utilizan como agentes de contraste para visualización y detección de tumores cancerígenos; en el área biológica se usan las nanopartículas como agentes antimicrobiales en empaques activos de alimentos y así también en el diseño de biosensores para detección de contaminantes tóxicos como pesticidas, entre otros (Barrera et al., 2009).

Las nanopartículas de plata han tenido una exploración muy grande con el pasar del tiempo, por ejemplo, empezaron a actuar como agente inhibidor del crecimiento de microorganismos en los siglos XVII y XVIII, empleando el nitrato de plata para la curación de heridas y el tratamiento de úlceras (Monge, 2009). Por otro lado, diferentes estudios relacionados con las síntesis de AuNPs por medio de extractos naturales han reportado la presencia y eficiencia de la propie- dad antimicrobial como base de estudio. Ramamurthy et al. (2013), reportaron la síntesis de AuNPs usando el extracto acuoso de Solanum toroum, estas nanopartículas sintetizadas presentaron fuertes radicales libres y actividad antimicrobial. MubarakAli et al. (2011), lograron que las nanopartículas de oro sintetizadas por medio de las hojas de Mentha piperita se activen en presencia de patógenos humanos como Staphylococcus aureus y Escherichia coli. Por último, Muthuvel et al. (2014) ilustró la síntesis de AuNPs a partir del extracto de las hojas de Solanum nigrum, donde estas presentaron un efecto antioxidante. Finalmente el estudio de MubarakAli et al. (2011), antibacterial frente a diferentes patógenos humanos.

Aun así, la síntesis e implementación de nanopartículas de oro (AuNPs) es un área en expansión comparandose con las nanopartículas de plata. Por ello, el presente trabajo plantea como objetivo principal evaluar cualitativamente la propiedad antimicrobial de las nanopartículas de oro sintetizadas, con el fin de implementarse en empaques activos de alimentos como agente inhibidor del crecimiento de microorganismos que favorecen la descomposición rápida de los alimentos perecederos. Para llevar a cabo el estudio se establecieron dos etapas principales: la primera corresponde a la biosíntesis de nanopartículas de oro por medio de un método biológico con extractos de dos plantas de Tamarindus indica L y Mangifera indica L. Como segunda etapa, se evaluó cualitativamente la propiedad antimicrobial de estas nanopartículas por medio de tres métodos: el medio de cultivo modificado, el sembrado en superficie y la prueba de difusión por disco. Dentro de esta última etapa se identificaron los diferentes microorganismos presentes en todas las pruebas (en caso de presencia), y se refirió a cuál sería la concentración adecuada de nanopartículas de oro para actuar como inhibidores de microorganismos.

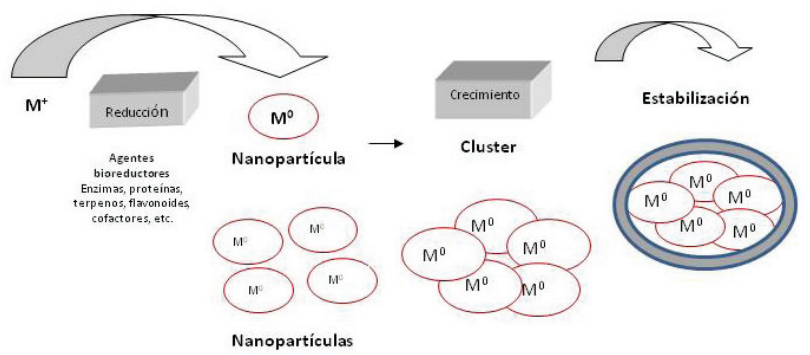

Figura 1. Formación de nanopartículas de oro (Síntesis). Fuente: adaptado de Kumar et al. (2013) 


\section{Metodología}

El desarrollo de la metodología se dividió en dos fases principales, la primera está relacionada con la síntesis y formación de nanopartículas de oro, efectuando un análisis tecnológico de microscopia electrónica de barrido (MEB) posteriormente a la biosíntesis para identificar su formación. La segunda fase, toma relevancia gracias a que es el foco principal de nuestro estudio. En esta se realizan tres diferentes pruebas de cultivos para observar el crecimiento y la inhibición microbiana de los diferentes microorganismos; identificando cualitativamente los tipos de microorganismos presentes y la posible concentración de AuNPs para inhibir su crecimiento. En las siguientes subsecciones se describen con más claridad las dos fases.

\section{BIOSíNTESIS DE NANOPARTíCULAS DE ORO}

Para la biosíntesis se seleccionaron las hojas de Tamarindus indica L. (T. indica) y Mangifera indica L. (M. indica), obtenidas de árboles frutales localizados en la ciudad de Arroyo Grande del departamento de Bolívar, Colombia. La infusión se realizó a partir del material vegetal recolectado con agua destilada. Posteriormente se sintetizaron las nanopartículas de oro por medio del método reportado por Correa et al. (2015), con un tiempo aproximado de reacción entre 10-15 minutos a temperatura ambiente e un $\mathrm{pH}$ de 5.6. Se emplearon los extractos de las hojas en fase acuosa, ácido cloroáurico (HAuCl4) con una concentración de $0.27 \mathrm{mM}$ e hidróxido de sodio $(\mathrm{NaOH})$ a una concentración de $1 \mathrm{M}$. La mezcla homogénea resultante de la síntesis se centrifugó con el fin de sedimentar el material solido (nanopartículas de oro), después se extrajo y se lavó con agua destilada. Este último procedimiento se repitió dos veces con el objetivo de eliminar la mayor cantidad de impurezas. Finalmente, el material sólido se extrajo para formar una solución homogénea de AuNPs-Bio en fase acuosa (Correa et al., 2016).

\section{MicROSCOPÍA ELECTRÓNICA DE BARRIDO (MEB)}

Posterior a la síntesis, se procedió a realizar un análisis a la solución acuosa final, con el fin de identificar la presencia y tamaño de AuNPs, y proseguir a la verificación de la propiedad antimicrobial. Este análisis se realizó en un Microscopio Electrónico Quanta FEG 650 ambiental (MEB), trabajado en el modo de alto vacío y utilizando el detector de electrones secundarios "Everhart Thornley Detector" (ETD) y el detector de electrones retrodispersados "Backscater Electron Detector"
(BSED). Los análisis químicos puntuales se realizaron debido a que el instrumento se acopla a un detector EDAX APOLO X que tiene una resolución de $126.1 \mathrm{eV}$ (en. Mn K $\alpha$ ) para realizar análisis EDS (Energy Dispersive Spectroscopy), proporcionando información cualitativa y semi-cuantitativa de los elementos químicos presentes en la muestra analizada.

\section{PropiedAD ANTIMICROBIAL DE LAS NANOPARTíCULAS DE ORO}

Para determinar la propiedad antimicrobial de las nanopartículas de oro se llevaron a cabo tres tipos de metodología. Todos los medios de cultivo elaborados para los diferentes procedimientos se desarrollaron en cajas Petri con agar nutritivo MERCK.

\section{MeDIO DE CULTIVO MODIFICADO}

El medio de cultivo modificado consistió en incorporar la solución de nanopartículas de oro de los extractos de T. indica L. y M. indica L. en el medio de cultivo (agar nutritivo). Inicialmente se estableció un blanco, donde el agar nutritivo no contenía la solución de AuNPs. Para la elaboración de los medios, se adicionaron $0.5 \mathrm{~mL}$ de la solución de nanopartículas de oro a $25 \mathrm{~mL}$ de agar nutritivo, el cual se encontraba a una temperatura de $40^{\circ} \mathrm{C}$. Después de la mezcla y vertido en las cajas Petri, se dejó enfriar a temperatura ambiente. Los medios de cultivo preparados antes de ser incubados se expusieron al entorno durante 5 minutos. Posteriormente se incubaron a una temperatura de $37^{\circ} \mathrm{C}$ por 48 horas. Esta metodología se realizó nuevamente, variando el volumen de la solución de AuNPs a $1 \mathrm{~mL}$, para evaluar las posibles diferencias en el crecimiento microbiano.

\section{SEMBRADO EN SUPERFICIE}

Inicialmente, el medio de cultivo se esterilizó en el autoclave por 80 minutos a $120^{\circ} \mathrm{C}$. Después de esterilizado se vertieron $25 \mathrm{ml}$ del medio en cada caja Petri y se solidificó a temperatura ambiente. Se adiciono $1 \mathrm{~mL}$ de la solución de nanopartículas de oro en la superficie esparcida uniformemente con un rastrillo de vidrio estéril, después se expuso al entorno durante 5 minutos. Por último se incubó por 48 horas a una temperatura de $37^{\circ} \mathrm{C}$.

\section{PRUEBA DE DIFUSIÓN POR DISCO}

La prueba de difusión por disco se basó en el estudio de BauerKirby (1966), que se adoptó por el Comité Nacio- 
nal para la Normatización de Laboratorios Clínicos (NCCLS) (OPdl, 2010).

El procedimiento se realizó de acuerdo con los siguientes pasos:

- Seleccionar las colonias

- Preparar una suspensión del inóculo

- Estandarizar la suspensión del inóculo

- Inocular la placa

- Colocar discos antimicrobianos

- Incubar la placa

- Medir las zonas de inhibición e interpretar los resultados

Se utilizaron cinco tipos de colonias obtenidas en los procedimientos anteriores y se preparó el medio sólido para el cultivo celular. Posteriormente, el medio se esterilizó en el autoclave por 80 minutos a $120^{\circ} \mathrm{C}$. Después de esterilizado se vertieron $25 \mathrm{ml}$ del medio en cada caja Petri. El medio se inoculó a $1 \mathrm{~mL}$ de las cinco colonias escogidas en una solución salina al $0.89 \%$ durante 1 hora a una temperatura de $37^{\circ} \mathrm{C}$. Después, se esparció uniformemente $0.5 \mathrm{~mL}$ del inoculo bacteriano en la superficie de las cajas Petri utilizando un rastrillo de vidrio estéril y se incubó por 30 minutos. Se colocaron tres filtros de papel previamente humedecido con 1, 2 y 3 gotas de la solución de nanopartículas de oro dentro de la caja de Petri. Este procedimiento se realizó tanto para la solución de nanopartículas de oro de sintetizadas con extracto de las hojas de T. indica L. y M. indica L. Las cajas Petri con sus respectivos discos se incubaron a una temperatura de $37^{\circ} \mathrm{C}$ para la posterior verificación de la propiedad antimicrobial, por un tiempo de 24 horas.

\section{IDENTIFICACIÓN CUALITATIVA DE LOS MICROORGANISMOS} PRESENTES

\section{BACTERIAS}

Para esta prueba se utilizó la metodología del manual de "métodos de identificación bacteriana en el laboratorio de microbiología" de la sociedad española de enfermedades (2010). Basándonos en él, la identificación bacteriana se realizó por medio de métodos convencionales, teniendo en cuenta sus características fenotípicas (método cualitativo), ya que su realización y coste los hace más asequibles. Según Cercenado y Cantón, (2010), los esquemas tradicionales de identificación fenotípica bacteriana se basan en las características observables de las bacterias, como su morfología, desarrollo, y propiedades bioquímicas y metabólicas. En este caso, únicamente se indicarán cuál es el género y la especie a la que la bacteria identificada tiene mayor probabilidad de pertenecer. Inicialmente se describieron las características fenotípicas (macroscópicas) como su tamaño, forma, consistencia y color; de acuerdo con esto, se aislaron a un cultivo puro para ver mejor su desempeño. Se prosiguió a realizar una tinción de Gram, que fue el método más amigable y empledo para su identificación. Segundo, se prosiguió a la identificación de género y por último la identificación de la especie (Olmos et al., 2010).

\section{HONGOS}

Para la identificación de las especies de hongo, fue necesario realizar principalmente una observación macroscópica del hongo para determinar el tamaño de la colonia, diámetro, textura, lanosa, granulosa, color, entre otros; y en segundo lugar una observación microscópica para determinar caracteres microscópicos del micelio fúngico.

\section{ReSULTADOS Y DISCUSIÓN}

\section{ANÁLISIS MEB PARA EL EXTRACTO DE T. INDICA Y M. INDICA}

Las soluciones de AuNPs en medio acuoso tuvieron una concentración de nano partículas de $1.1 \mathrm{mg} / \mathrm{mL}$ para el extracto de hojas de Tamarindus indica L. y 0.9 $\mathrm{mg} / \mathrm{mL}$ para el extracto de hojas de Mangifera indica $L$. La figura 2 ilustra las micrografías electrónicas de barrido efectuadas por análisis de MEB de las nanopartículas biosintetizadas a partir T. indica y $M$. indica, respectivamente al extracto, mientras que la tabla 1 presenta los datos obtenidos sobre la concentración de los elementos presentes en las muestras a partir del análisis por energía dispersa (EDX).

Las micrografías muestran una buena distribución de las nanopartículas, su forma esférica y un tamaño uniforme promedio de $52 \pm 5$ y $78 \pm 7 \mathrm{~nm}$, que es un tamaño adecuado para una concentración inicial tan baja como $0.27 \mathrm{mM}$ en los dos casos. Las AuNPs-bio con M. indica presentan pequeños sectores de aglomeración y un tamaño mayor respecto a las AuNPs-bio con T. indica. 
Tabla 1. Composición elemental de los extractos de T. indica y M. indica con nanopartículas de oro medidos por EDX

\begin{tabular}{ccc}
\hline Extracto & Elemento & $\%$ \\
\hline \multirow{3}{*}{ Tamarindus indica L. } & $\mathrm{C}$ & 71.87 \\
& $\mathrm{O}$ & 13.40 \\
& $\mathrm{Na}$ & 00.35 \\
& $\mathrm{Al}$ & 00.48 \\
& $\mathrm{Si}$ & 00.63 \\
& $\mathrm{Ca}$ & 00.39 \\
& $\mathrm{Au}$ & 12.88 \\
\hline Mangifera indica L. & $\mathrm{C}$ & 77.16 \\
& $\mathrm{O}$ & 11.23 \\
& $\mathrm{Au}$ & 11.61
\end{tabular}

Fuente: Autores

El resultado del análisis del EDX confirma que las nanopartículas de oro referentes están presentes con $12.87 \%$ y $11.61 \%$ del peso de la muestra analizada para el extracto de las hojas de T. indica y M. indica, respectivamente. La muestra de la solución acuosa de las nanopartículas de oro, referente al extracto de $T$. indica, presentó componentes orgánicos como Carbono, Oxigeno, Sodio, Aluminio, Sílice y Calcio, correspondientes a la composición fitoquímica de la planta. Por otro lado, la solución de AuNPs-Bio con el extracto de $M$. indica presentó únicamente componentes como Carbono y Oxigeno en gran proporción.

\section{Propiedad antimicrobial de LAS NanOpartículas De ORO}

Para las pruebas de medio de cultivo modificado y sembrado en superficie se utilizó un medio de cultivo control sin adición de la solución de AuNPs. La muestra control presentó crecimiento de cinco colonias de coloración blanca correspondientes únicamente a bacterias.

a) SEM Tamarindus indica $L$.

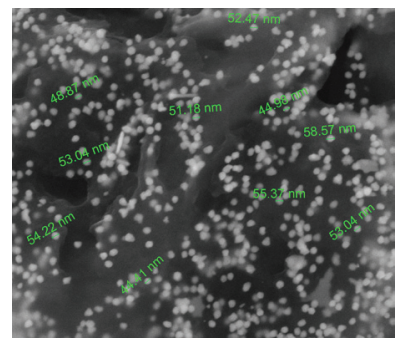

b) SEM Magnifera indica $L$.

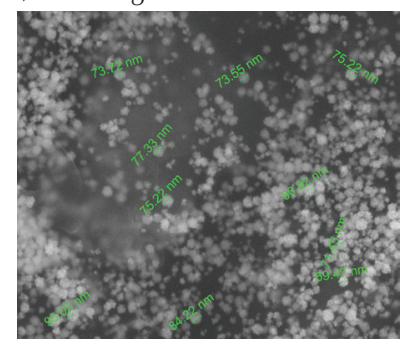

Figura 2. Micrografía representativa de la MEB de las nanopartículas de oro sintetizadas a partir del $\mathrm{HAuCl}_{4}$ con una concentración de $0.27 \mathrm{mM}$ y extracto de hojas de: a) Tamarindus indica $L$., b) Mangifera indica L. Fuente: Autores
ANÁLISIS DE LA PROPIEDAD ANTIMICROBIAL POR MEDIO DE CULTIVO MODIFICADO

Para este método, se realizaron dos medios de cultivo con diferentes dosis de la solución de nanopartículas (SAuNPs), para el medio A se adicionaron $0.5 \mathrm{~mL}$ y para el medio B $1 \mathrm{~mL}$. Las muestras presentaron crecimiento de hongos y colonias de bacterias en superficie y a profundidad de coloración blanca en todas las pruebas. Los resultados obtenidos se muestran en la figura 3, representando el crecimiento de bacterias en coloración verde y el crecimiento de hongos en coloración naranja.

Se evidenció el crecimiento de bacterias color blanco-crema de forma uniforme circular, con tamaños variados, hongos de coloración blanca con tamaños y dispersión diferentes. Los microorganismos presentes en el medio modificado $\mathbf{A}$, tanto para la muestra de $T$. indica $L$. y $M$. indica $L$, cubre en su totalidad la superficie del medio. En el medio modificado B, se presenta una disminución en el crecimiento de microorganismos. La prueba con la solución de nanopartículas a partir del extracto de $M$. indica $L$, en el medio de cultivo B presenta un menor crecimiento de microorganismo a diferencia del medio de cultivo B con presencia de la S- AuNPs a partir de $T$. indica $L$.

Con los resultados obtenidos se puede decir que a mayor volumen adicionado de la solución acuosa de nanopartículas, el crecimiento microbiano es menor. La SAuNPs obtenida a partir del extracto de $M$. indica, a comparación de la de T. indica, evidencia una mayor inhibición de microorganismos en sus pruebas. Esto puede deberse a que en la muestra de T. indica se presentan mayor variedad de compuestos orgánicos; la presencia o ausencia de los diferentes compuestos orgánicos, azucares y proteínas que contienen directamente las hojas con las que se elaboraron los extractos naturales pueden alterar la propiedad antimicrobial de las nanopartículas. Según Chunekar (2010), los grupos carbonilo de proteínas que se encuentran en las plantas tienen una fuerte afinidad para unirse a metales, así el extracto de plantas puede llegar a actuar como agente de protección terminal y cubrir la superficie de las nanopartículas sintetizadas (figura 4), disminuyendo su área superficial al adherirse, por consiguiente, su capacidad antimicrobiana.

Esta variedad de compuestos orgánicos presentes en la muestra de AuNPs-Bio del extracto de T. indica se debe, principalmente, a las propiedades fitoquímicas de las hojas y posiblemente a que en el procedimiento de síntesis únicamente se realizó el lavado del material de nanopartículas con agua destilada y no con solventes orgánicos que tuvieran la capacidad de eliminar o capturar dichas impurezas que afectan este aspecto. 
Tamarindus indica $L$.
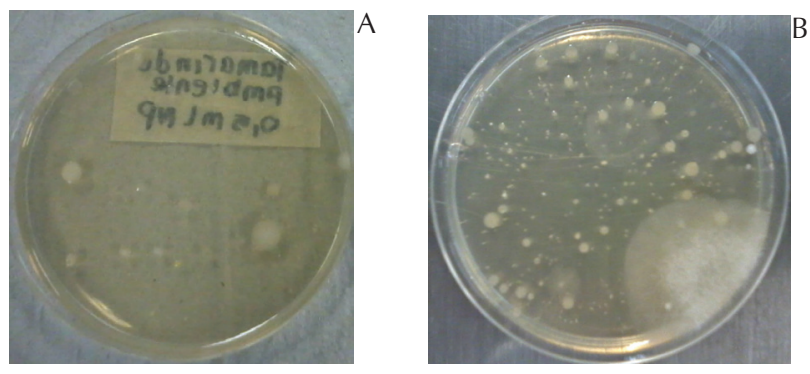

Mangifera indica $L$.
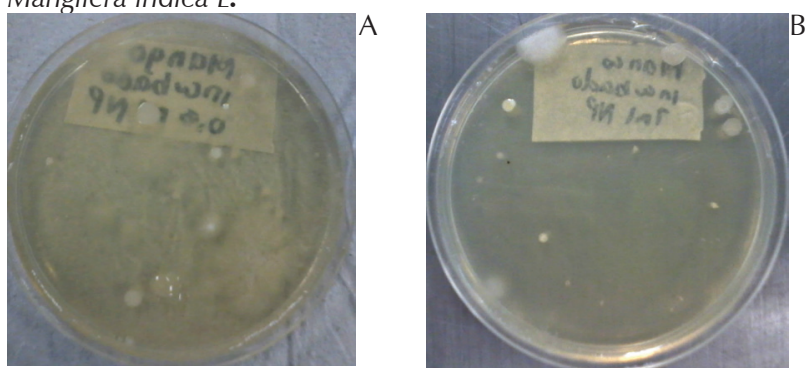

Figura 3. Prueba de medio de cultivo modificado con la S-AuNPs provenientes del extracto Tamarindus indica L. y Magnifera indica L. incubados a $37^{\circ} \mathrm{C}$ por 48 horas, a) 0.5 $\mathrm{ml}$ de adición de S-AuNPs, b) $1 \mathrm{ml}$ de adición de S-AuNPs. Fuente: Autores

Por otro lado, estos resultados se pueden corroborar y comparar con el estudio realizado por Muthuvel et al. (2014), dando sustento a lo anteriormente planteado, confirmando que el punto máximo de inhibición del crecimiento microbiano se debe a los diferentes compuestos fitoquímicos presentes en las hojas implementadas para la síntesis.

ANÁLISIS DE LA PROPIEDAD ANTIMICROBIAL POR MEDIO DEL SEMBRADO DE SUPERFICIE

Para el sembrado en la superficie se utilizaron los resultados obtenidos del cultivo modificado, empleando $1 \mathrm{~mL}$ de la solución de AuNPs. En los resultados se evidenció un mayor crecimiento de microorganismos que en la muestra control. La figura 5 expone los resultados obtenidos de la prueba de sembrado en superficie.

En estos resultados se evidencia el crecimiento de bacterias de coloración blanca, con relieve, aspecto lizo y una forma regular uniforme, muy similares al método anterior, pero con una menor proporción. Esta menor proporción permite observar los espaciamientos y límites entre las colonias de bacterias. A pesar de que se pueden observar colonias bacterianas individuales, su

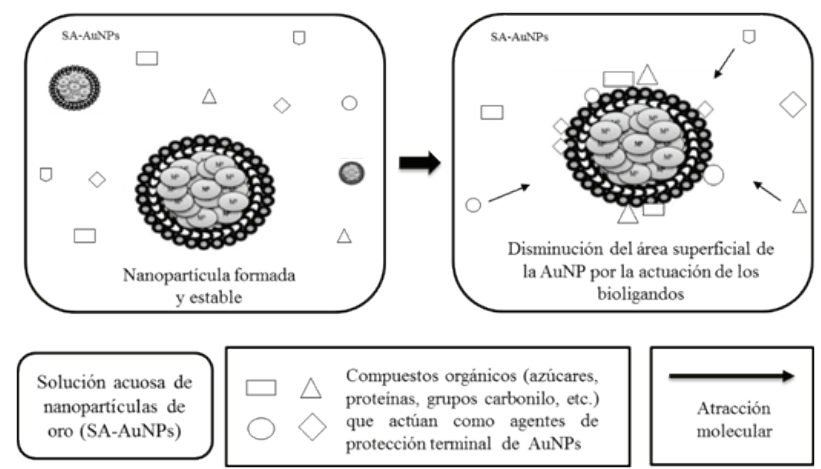

Figura 4. Esquema general de mecanismos de inhibición de la propiedad antimicrobial de las nanopartículas de oro (AuNPs). Fuente: Autores

tamaño, aglomeración y la presencia de bacterias con un desplazamiento estilo swimming (Hernández y Rodríguez, 1999; Uma et al., 2015), hace imposible su identificación cualitativa. A su vez, el crecimiento de un hongo filamentoso en la muestra de T. indica, D coloración blanca, hace imposible la verificación de cuantas colonias se encuentren a su alrededor. La muestra de $T$. indica presenta mayor variedad y cantidad relacionados con el crecimiento de microorganismos en comparación con la muestra realizada con $M$. indica.

Este segundo análisis soporta los resultados obtenidos en la prueba anterior. La presencia de diferentes compuestos orgánicos y proteínas en las hojas de T. indica facilitan el crecimiento de microorganismos inhibiendo la propiedad antimicrobial de las AuNPs. A su vez, al usar $1 \mathrm{~mL}$ de la solución en únicamente la superficie del medio, proporciona una menor área de trabajo, menor distribución y mayor concentración de AuNPs, lo cual mejora su rendimiento, aumentando su capacidad antimicrobial.

Tamarindus indica $L$.

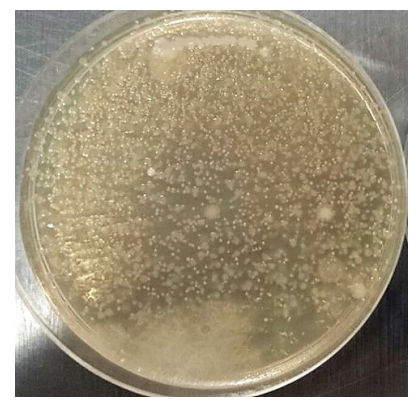

Figura 5. Prueba de sembrado en superficie con $1 \mathrm{~mL}$ de la S-AuPs biosintetizadas a partir del extracto de Tamarindus indica L. y Mangifera indica L. Fuente: Autores

Mangifera indica $L$.

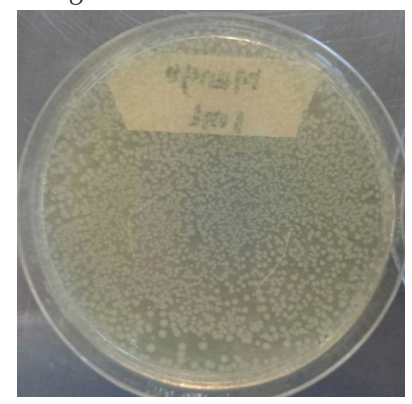
. 

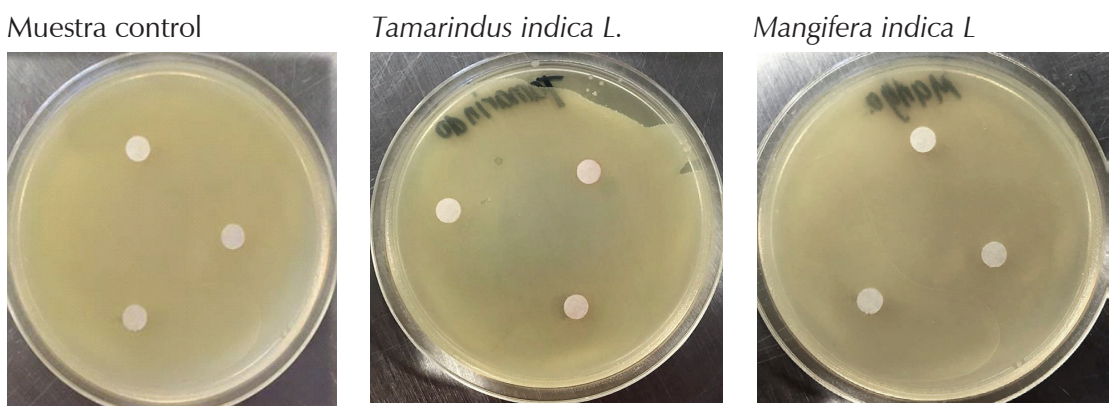

Figura 6. Prueba de difusión por disco con medio incubado a $37^{\circ} \mathrm{C}$ por 24 horas. Evaluado con muestra control e S-AuNPs a partir de Tamarindus indica L. y Mangifera indica L. Fuente: Autores

ANÁLISIS DE LA PROPIEDAD ANTIMICROBIAL POR MEDIO DE LA PRUEBA DE DIFUSIÓN POR DISCO

Con el objetivo de corroborar los resultados obtenidos en las dos pruebas anteriores se realizó la prueba de difusión por disco. En la figura 6 se presentan los resultados obtenidos de la prueba de difusión por disco del control (24 horas después de incubada) y los resultados obtenidos con las soluciones de nanopartículas de oro biosintetizadas a partir de T. indica y M. indica.

Después de 24 horas de incubación del medio con las AuNPs-Bio, se puede observar que para los dos extractos de planta, la propiedad antimicrobial de las nanopartículas de oro no está presente debido a que no se formaron los halos de inhibición de crecimiento bacteriano. El crecimiento es evidente y cubre uniformemente la totalidad de la superficie del medio de cultivo tomando una textura rugosa y opaca para T. indica y para M. indica.

Los estudios realizados por Muthuvel et al. (2014) y Uma et al. (2015), dan sustento a lo anteriormente planteado, ya que exponen que la inhibición es dependiente de la dosis de nanopartículas y a los diferentes compuestos fitoquímicos presentes en las hojas implementadas para la síntesis.

\section{IDENTIFICACIÓN CUALITATIVA DE MICROORGANISMOS}

Las bacterias y hongos obtenidos en el presente trabajo se identificaron por sus características fenotípicas como: coloración, relieve y textura, entre otras. En este caso fue posible identificar colonias de bacterias como: Sthaphylococcus (S. aureus), Enterobacterias (Especie Proteus mirabilis y vulgaris), Bacillus sp (especie Bacillos Subtillis) y hongos como: Microsporum canis y Fusarium sp. En la tabla 2 se presentan las bacterias y hongos identificados de acuerdo con sus características fenotípicas.

Se ha reportado que las nanopartículas de oro presentan propiedad antimicrobial contra Candida Albicans (Huang et al., 2007), Pseudomonas aeruginosa, Escherichia coli y Acinetobacter baumannii (Ghosh et al., 2012) y E. coli y S. aureus ( Ali et al., 2011). Pero aún no se reportan casos en los que se evidencien estos mismos microorganismos identificados en el presente trabajo.

\section{Conclusiones}

El análisis por MEB demostró que es posible sintetizar nanopartículas de oro a partir de extractos de las hojas de Tamarindus indica L. y Mangifera indica L. con la sal precursora ácido cloroáurico (HAuCl4) como agente reductor, obteniendo un tamaño promedio de $52 \pm 5$ y $78 \pm 7 \mathrm{~nm}$, respectivo al extracto. En general, se observó crecimiento de microorganismos en todas las pruebas donde estaban presentes las AuNPs provenientes de los extractos de T. indica y $M$. indica. Esto corroboró que la propiedad antimicrobial de las AuNPs se presenta a concentraciones mayores de $1.1 \mathrm{mg} / \mathrm{mL}$ y $0.9 \mathrm{mg} / \mathrm{mL}$ como lo reporta la literatura, alrededor de los $45 \mathrm{mg} / \mathrm{mL}$. Las impurezas relacionadas con los compuestos orgánicos provenientes de los extractos de plantas favorecieron en el crecimiento de microorganismos como nutrientes para los mismos. A su vez, los extractos naturales contienen proteínas que pueden actuar como bioligandos y agentes de protección terminal, protegiendo así las nanopartículas, disminuyendo su área superficial y opacando su propiedad antimicrobial. Los resultados evidencian que si se elaboran soluciones de nanopartículas más concentradas serían un potencial candidato para actuar como agentes antimicrobianos.

\section{RefERENCIAS}

Aguilar M. Síntesis y caracterización de nano-partículas de plata: Efecto sobre Colletotricum gloesporioides, (tesis Mag.Sc.), Instituto Politécnico Nacional, 2009, Centro de Investigación en Ciencia Aplicada y Tecnología Avanzada, 90 p.

Ali D.M., Thajuddin N., Jeganathan K., Gunasekaran M. Plant extract mediated synthesis of silver and gold nanoparticles and its antibacterial activity against clinically isolated pathogens. Colloids Surf B Biointerfaces, volumen 85, 2011: 360-365. 
Tabla 2. Características fenotípicas de bacterias y hongos identificados en las pruebas antimicrobianas

\begin{tabular}{|c|c|c|c|}
\hline $\begin{array}{l}\text { Microorganismos } \\
\text { identificados }\end{array}$ & Identificación de la especie & $\begin{array}{l}\text { Clasificación de } \\
\text { Gram }\end{array}$ & Características identificadas \\
\hline $\begin{array}{l}\text { Sthaphylococcus } \\
\text { (Bacteria) }\end{array}$ & $\begin{array}{l}\text { La especie S. aureus (patógena). } \\
\text { Produce enzimas extracelulares } \\
\text { y toxinas }\end{array}$ & cocos grampositivos & $\begin{array}{l}\text { Células esféricas con agrupación } \\
\text { irregular. Colonias redondas, lisas, } \\
\text { elevadas, con variaciones desde color } \\
\text { gris, blanco hasta amarillo intenso } \\
\text { (Marrero et al., 2006). }\end{array}$ \\
\hline $\begin{array}{l}\text { Enterobacterias } \\
\text { (Bacteria) }\end{array}$ & $\begin{array}{l}\text { Proteus ( } P \text {. mirabilis, } P \text {. vulgaris) } \\
\text { Forman parte de la flora } \\
\text { intestinal del hombre y animales } \\
\text { adicionalmente se encuentran } \\
\text { distribuidos en la naturaleza }\end{array}$ & $\begin{array}{l}\text { Bacilos } \\
\text { Granm-negativos } \\
\text { Enterobacterias }\end{array}$ & $\begin{array}{l}\text { Colonias medianas, convexas, } \\
\text { blanquecinas o translucidas, forma } \\
\text { circular, bordes redondeados hay } \\
\text { presencia de efecto swarming } \\
\text { (Hernández y Rodríguez, 1999; Marrero } \\
\text { et al., 2006). }\end{array}$ \\
\hline $\begin{array}{l}\text { Bacillus sp } \\
\text { (Bacteria) }\end{array}$ & $\begin{array}{l}\text { (Bacillos Subtillis) } \\
\text { Este microorganismo tiene } \\
\text { capacidad para controlar ciertas } \\
\text { enfermedades en cultivos } \\
\text { vegetales }\end{array}$ & $\begin{array}{l}\text { Bacilos Gram } \\
\text { positivo }\end{array}$ & $\begin{array}{l}\text { Colonias Grandes, planas, blanquecinas, } \\
\text { forma irregular, bordes lobulados, dan } \\
\text { la apariencia de estar secas, algunas } \\
\text { colonias con apariencia de huevo } \\
\text { estrellado (Bartram et al., 2003). }\end{array}$ \\
\hline $\begin{array}{l}\text { Microsporum canis } \\
\text { (Hongo) }\end{array}$ & & & $\begin{array}{l}\text { Colonias con micelio blanco, } \\
\text { algodonosas, planas y radiadas. Hongo } \\
\text { filametoso que presenta microconidios } \\
\text { abundates, fusiforme, grandes, con } \\
\text { micelio blanco, aspecto lanoso, bordes } \\
\text { desflecado y centro polvoriento } \\
\text { (Sarmiento y Trujillo, 2006). }\end{array}$ \\
\hline $\begin{array}{l}\text { Fusarium sp } \\
\text { (hongo) }\end{array}$ & $\begin{array}{l}\text { Las especies de Fusarium } \\
\text { pueden causar varias infecciones } \\
\text { en humanos. }\end{array}$ & & $\begin{array}{l}\text { Hongo filamentoso aislado de plantas y } \\
\text { suelo. Pueden ser algodonosas de color } \\
\text { blanco, con diversos pigmentos según la } \\
\text { especie. Se encuentra como microbiota } \\
\text { normal en arroz, frijol, soya y otros } \\
\text { cultivos. Es un contaminante común y } \\
\text { fitopatógeno (Tangarife, 2011). }\end{array}$ \\
\hline
\end{tabular}

Fuente: Revisión bibliográfica de los autores

Arizaga N., Ibarz G., Piñol R. Journal of Colloid and Interface Sci., volumen 348, 2010: 832.

Barrera C., Herrera A., Rinaldi C. Journal of Colloid and Interface Sci., volumen 329, 2009: 07.

Chunekar K. Bhavprakash Nighantu. Chaukhambha Bharati Academy. 2010, pp. 33-34.

Bartram J. et al. (Eds.). Heterotrophic plate counts and drinkingwater safety: the significance of HPCs for water quality and human health, Series de la OMS Emerging Issues in Water and Infectious Disease, IWA Publishing, 2003.

Basavaraja S., Balaji S., Lagashetty A., Rajasab A. Extracellular biosynthesis of silver nanoparticles using the fungus Fusarium semitectum. Mater Res Bull, volumen 43, 2008: 1164-1170.

Correa S.N., Naranjo A.M., Herrera A.P. Biosynthesis and characterization of gold nanoparticles using extracts of Tamarindus indica L leaves. Journal of Physics: Conference Series, vol. 687, 2016.

Ghosh S., Patil S., Ahire M., Kitture R., Kale S., Pardesi K., et al. Synthesis of silver nanoparticles using Dioscorea bulbifera tuber extract and evaluation of its synergistic potential in com- bination with antimicrobial agents, Int J Nanomed, volumen 7, 2012: 483-96.

González M., Villabuena-Ibáñez M., Bazzi R. Preparación de nanopartículas y nanoestructuras luminiscentes de y2 O3: Eu3+, Tb3+ usando el método poliol. Bol. Soc. Esp. Ceram., volumen 48 (número 3), 2009: 141-146.

Hernández F. y Rodríguez E. El fenómeno de "swarming" y otros tipos de desplazamiento bacteriano. Revista rccm, volumen 14, 1999: 1-2 [en línea]. Disponible en:

http://www.hvil.sld.cu/bvs/archivos/215_guia\%20para\%20 la\%20identificacion\%20de\%20las\%20bacteria.pdf

Huang J.L., Li Q.B., Sun D.H., Lu Y.H., Su Y.B., Yang X., et al. Biosynthesis of silver and gold nanoparticles by novel sundried Cinnamomum camphora leaf. Nanotechnology, volumen 18, 2007 [en línea]. Disponible en: http://dx.doi.org/10.1088/ 0957-4484/18/10/105104. [Article 105104]

Kumar-Mittal A., Yusuf C., Chand-Banerjee U. Synthesis of metallic nanoparticles using plant extracts, Biotechnology Advances, volumen 31, 2013: 346-356. 
Marrero D. et al. Guía para la identificación de las bacterias más frecuentes en el laboratorio de microbiología clínica, 2006.

Monge M. Nanopartículas de plata: métodos de síntesis en disolución y propiedades bactericidas, Real Sociedad Española de Química, 2009, pp. 33.

MubarakAli D., Thajuddin N., Jeganathan K., Gunasekaran M. Plant extract mediated synthesis of silver and gold nanoparticles and its antibacterial activity against clinically isolated pathogen. Colloids Surf B Biointerfaces, volumen 85, 2011: 360-365.

Muthuvel A., Adavallan K., Balamurugan k., Krishnakumar N. Biosynthesis of gold nanoparticles using Solanum nigrum leaf extract and screening their free radical scavenging and antibacterial properties. Biomedicine \& Preventive Nutrition, volumen 4, 2014: 325-332.

Olmos-Fernández A., De la Fuente-García C., Saéz J.A., RamosNieto S.V.. Procedimientos en Microbiología Clínica, Métodos de identificación bacteriana en el laboratorio de microbiología, Recomendaciones de la Sociedad Española de Enfermedades Infecciosas y Microbiología Clínica, 2010.

OPdl. S. 2010. Recuperado el 24 de agosto de 2015 [en línea]. Disponible en: www.paho.org/spanish/ad/ths/ev/04.pdf.
Ramamurthy C.H., Padma M., Samadanam D.M.I., Mareeswaran R., Suyavaran A., Suresh- Kumar M, et al. The extra cellular synthesis of gold and silver nanoparticles and their free radical scavenging and antibacterial properties. Colloids Surf B Biointerfaces, volumen 102, 2013: 08-115.

Sarmiento C. y Trujillo M. Estabilización e implementación de las técnicas en el diagnóstico clínico de micosis cutáneas en el laboratorio de micología de la Pontificia Bolivariana Javeriana (trabajo de grado (Bacteriología)), Universidad Pontificia Javeriana, Facultad de Ciencias, 2006.

Sastry M., Ahmad A., Islam-Khan M., Kumar R. Biosynthesis of metal nanoparticles using fungi and actinomycete. Curr Sci., volumen 85, 2003:162-170.

Tangarife V. Fusarium spp, Escuela de Microbiología. Universidad de Antioquia, 2011 [en línea]. Disponible en: http://aprendeenlinea.udea.edu.co/lms/moodle/mod/resource/view.php?inpopup=true\&id=100813.

Uma-Suganya K.S. et al. Blue green alga mediated synthesis of gold nanoparticles and its antibacterial efficacy against Gram positive organisms. Materials Science and Engineering, volumen 47, 2015: 351-356. 


\section{Citación sugerida:}

\section{Citación estilo Chicago}

Naranjo-Herrera, Ana María, Sandra Natalia Correa-Torres, Adriana Patricia Herrera-Barros. Evaluación de la propiedad antimicrobial de las nanopartículas de oro sintetizadas con extractos de Tamarindus Indica L y Mangifera Indica L. Ingeniería Investigación y Tecnología, XVIII, 04 (2017): 389-398.

\section{Citación estilo ISO 690}

Naranjo-Herrera A.M., Correa-Torres S.N., Herrera-Barros A.P. Evaluación de la propiedad antimicrobial de las nanopartículas de oro sintetizadas con extractos de Tamarindus Indica $L$ y Mangifera Indica $L$. Ingeniería Investigación y Tecnología, volumen XVIII (número 4), octubre-diciembre 2017: 389-398.

\section{Semblanzas de los autores}

Ana María Naranjo-Herrera. Ingeniera ambiental por la Universidad Pontificia Bolivariana seccional Bucaramanga-Colombia. Actualmente es estudiante de maestría profesional de la Universidad Federal do Rio de Janeiro con énfasis en gestión ambiental.

Sandra Natalia Correa-Torres. Doctora en química aplicada por la Universidad de Puerto Rico. Obtuvo la maestría en química por la Universidad de Puerto Rico. Actualmente es docente en la Facultad de Ingeniería Ambiental y coordinadora de investigaciones en la Escuela de Ingenierías de la Universidad Pontifica Bolivariana seccional Bucaramanga-Colombia.

Adriana Patrícia Herrera-Barros. Obtuvo el pos-doctorado en síntesis y aplicaciones de nanomateriales multifuncionales de la Universidad de Puerto Rico. Cuenta con el doctorado en ingeniería química por la Universidad de Puerto Rico y la maestría en ingeniería química por la Universidad de Puerto Rico. Actualmente es jefa del Departamento de Investigación de la Facultad de Ingeniería de la Universidad de Cartagena-Colombia. 